\title{
Review
}

Journal of Innate

Immunity
J Innate Immun 2015;7:557-562

DOI: $10.1159 / 000375494$
Received: December 9, 2014

Accepted after revision: January 26, 2015

Published online: March 24, 2015

\section{Generation of Natural Killer Cell Memory during Viral Infection}

\author{
Timothy E. O'Sullivan ${ }^{a}$ Joseph C. Sun ${ }^{a, b}$ \\ ${ }^{\mathrm{a}}$ Immunology Program, Memorial Sloan Kettering Cancer Center, and ${ }^{\mathrm{b}}$ Department of Immunology and \\ Microbial Pathogenesis, Weill Cornell Medical College, New York, N.Y., USA
}

\section{Key Words}

Immunological memory · Natural killer cells .

Cytomegalovirus

\begin{abstract}
Immunological memory is classically regarded as an attribute of antigen-specific $T$ and $B$ lymphocytes of the adaptive immune system. Cells of the innate immune system, including natural killer (NK) cells, have been considered short-lived cytolytic cells that can rapidly respond against pathogens in an antigen-independent manner and then die off. However, NK cells have recently been described to possess traits of adaptive immunity, such as clonal expansion after viral antigen exposure to generate long-lived memory cells. In this review, we will discuss the current evidence for viral-induced NK cell memory in both mice and humans.
\end{abstract}

(c) 2015 S. Karger AG, Basel

\section{Introduction}

The ability of the immune system to rapidly respond and enhance the protection of the host against a previously encountered pathogen is defined as immunological memory. Long-lived memory cells are generated after an initial infection and display heightened responses upon a secondary challenge with the same pathogen. The process of memory formation in $\mathrm{T}$ cells has been well studied and is divided into 3 distinct phases [1]. Upon exposure to cognate antigen, naive $T$ cells clonally expand and differentiate into effector T cells during the 'expansion' phase. This first phase is followed by a second 'contraction' phase where the vast majority of effector T cells undergo apoptosis to form a small stable pool of surviving $\mathrm{T}$ cells that enter the third 'memory' phase. Memory T cells then persist throughout the host and maintain their longevity through self-renewal until a secondary encounter with their cognate antigen, when they exhibit enhanced proliferative and effector functions. Because cells of the innate immune system lack the ability to undergo somatic rearrangement of their receptor genes, it was hypothesized that these cells, including natural killer (NK) cells, lack antigen specificity and therefore could not form immunological memory. Work by our group and others has directly challenged this concept by establishing a view of NK cell memory that is based on viral antigen-driven proliferation through specific ligand/receptor interaction, which then generates a long-lived memory population with an enhanced ability to respond and protect against secondary viral challenges.

\section{KARGER 125\%}

(C) 2015 S. Karger AG, Basel

$1662-811 \mathrm{X} / 15 / 0076-0557 \$ 39.50 / 0$

E-Mail karger@karger.com

www.karger.com/jin
Dr. Joseph C. Sun

Memorial Sloan Kettering Cancer Center

408 East 69th Street, ZRC-1402

New York, NY 10065 (USA)

E-Mailsunj@mskcc.org 


\section{NK Cell Memory Formation in Response to MCMV Infection}

In recent years, NK cells have been appreciated to possess a number of developmental and functional features in common with cells of the adaptive immune system. These similarities include the development from a common lymphoid progenitor cell [2], a requirement for common $\gamma$-chain-dependent cytokines (e.g. IL-2, IL-7, and IL-15) during development and homeostasis [3], expression of the recombination-activating genes (RAGs) during ontogeny [4], and an education process in the bone marrow that is analogous to T-cell development in the thymus [5,6]. Moreover, much like their T-cell counterparts, which use the T-cell antigen receptor (TCR) to recognize antigens, NK cells also express activating receptors capable of directly binding virally derived antigens. For example, in C57BL/6 mice, the activating receptor Ly $49 \mathrm{H}$ is expressed on $\sim 50 \%$ of NK cells and binds the mouse cytomegalovirus (MCMV)-encoded glycoprotein m157 expressed on infected cells to drive the expansion of virus-specific NK cells during the acute phase of MCMV infection [7-11]. Using an experimental system in which $\mathrm{Ly} 49 \mathrm{H}+\mathrm{NK}$ cells were adoptively transferred into mice lacking this receptor, our group observed a robust antigen-driven expansion of these Ly $49 \mathrm{H}+$ cells after MCMV infection [12]. Following viral clearance, expanded effector NK cells underwent a rapid contraction phase to establish a long-lived memory pool of antigen-specific cells that could be recovered many months following infection in a variety of peripheral tissues [12]. These memory NK cells displayed functional attributes commonly associated with memory $\mathrm{T}$ cells such as secondary expansion, enhanced effector function ex vivo, and increased protection against virus challenges compared to naive NK cells from uninfected mice [12]. Most importantly, the expansion and memory formation of virus-specific NK cells was dependent on the interaction with the viral antigen, as MCMV lacking m157 glycoprotein did not induce Ly49H+ NK cell expansion or the development of memory after infection [12]. Indeed, Lanier and Min-Oo recently demonstrated that MCMV-primed memory NK cells display a reduced 'bystander' functionality after heterologous infections and cytokine-induced activation in the absence of m157 antigen, suggesting that memory Ly49H+ NK cells become specialized for the purpose of controlling MCMV upon reexposure [13]. Additional models of NK cell memory have been described in settings where mice have been primed with haptens or proinflammatory cytokines alone $[14,15]$. Together these results demonstrated that NK cells, like CD8+ T cells, undergo activation, expansion, and contraction in an antigen-specific manner to generate long-lived memory cells in response to viral infection.

\section{Mechanisms of Memory NK Cell Formation}

\section{Activation and Expansion}

Recent studies have also shed light on the molecular mechanisms controlling the formation of NK cell memory in response to MCMV infection. NK cells deficient in the IL-12 receptor or STAT4 signaling do not undergo clonal proliferation and are defective in memory NK cell generation following MCMV infection [16]. In addition, signals from proinflammatory cytokines (including IL12 , IL-18, and type I IFN) are necessary and sufficient to drive the expression of the transcription factor Zbtb32, which is essential for the proliferation and protective function of antigen-specific NK cells during MCMV infection [17]. Zbtb32 acts as an important molecular checkpoint to promote a proproliferative state in activated NK cells by antagonizing the tumor suppressor factor Blimp-1 [17]. Although the precise mechanisms of how Zbtb32 antagonizes Blimp-1 function in antigen-specific NK cells remain to be elucidated, the finding that proinflammatory cytokines are essential for maximal Zbtb32 expression provides a mechanistic explanation for how and why inflammatory signals are required for the robust proliferation of antigen-specific NK cells during MCMV infection, even when high amounts of viral antigen are present [16]. This pathway in NK cells may be analogous to 'signal 3' in the widely accepted model of T cell activation, which hypothesizes that 3 independent and coordinated signals from the T-cell antigen receptor (signal 1), costimulatory receptors such as CD28 (signal 2), and cytokine receptors such as IFNAR and IL-12R (signal 3) are required for maximal effector function [1]. Indeed, costimulatory activating signals are also required for the proliferation of antigen-specific NK cells in the presence of antigen and proinflammatory signals because Ly49H+ NK cells lacking the activating receptor DNAM-1 fail to expand and form long-lived memory cells following MCMV infection [18]. Thus, the signaling requirements to drive the optimal activation and proliferation of antigen-specific NK cells are analogous to their T-cell counterparts: receptor engagement with antigen (Ly49Hm157, signal 1), costimulatory signaling (DNAM-1, signal 2), and proinflammatory cytokine signaling (IL-12, STAT4, Zbtb32, signal 3) (fig. 1). Whether antigen-spe- 
cific NK cells require additional cytokine or costimulatory signals for clonal proliferation and memory formation will be interesting topics for future research.

\section{Contraction}

Induction of apoptosis in effector CD8+ T cells following viral clearance is an essential mechanism to prevent immune-mediated pathology by regulating the numbers of cytolytic lymphocytes [19], and therefore the contraction phase may also be a critical determinant in the development of NK cell memory in response to viral infection. During T-cell memory formation, Bcl-2 family proteins such as Bcl-2 and Bim play contrasting roles in the survival of antigen-specific effector T cells [20-22]. Similarly, effector NK cells require Bim-mediated proapoptotic signaling during the contraction phase to form a stable pool of memory cells [23]. Although it has been shown that prosurvival cytokines, such as IL-15, are required for the survival of adoptively transferred $\mathrm{Ly} 49 \mathrm{H}+$ effector NK cells [24], the protective pathways that antigen-specific NK cells use to combat apoptosis and mediate survival to form memory cells remain to be fully addressed (fig. 1). Our group has demonstrated that expression of microRNA-155 in virus-specific NK cells functions to suppress Noxa and suppressor of cytokine signaling 1 (SOCS1) during NK cell activation and expansion to enhance survival in response to MCMV infection (fig. 1) [25]. Recent studies have also demonstrated that the selfcatabolic process of autophagy is required for the survival of antigen specific CD8+ T cells in the effector-memory transition phase in response to viral infections [26,27]. Therefore, given the functional similarities between NK cells and CD8+ T cells, it will be of interest to investigate whether autophagy plays a critical role in the survival of virus-specific NK cells during the contraction phase, and to further understand the molecular mechanisms behind how autophagy mediates the formation of long-lived innate and adaptive lymphocytes.

\section{NK Cell Memory Formation in Response to Other Viral Infections}

In addition to evidence supporting NK cell memory formation during MCMV infection, several recent studies have suggested that NK cells are essential for secondary responses in other viral infections. Adoptive transfer experiments in mice have demonstrated that CXCR6+ hepatic NK cells primed with virus-like particles are sufficient and required for protective recall responses against

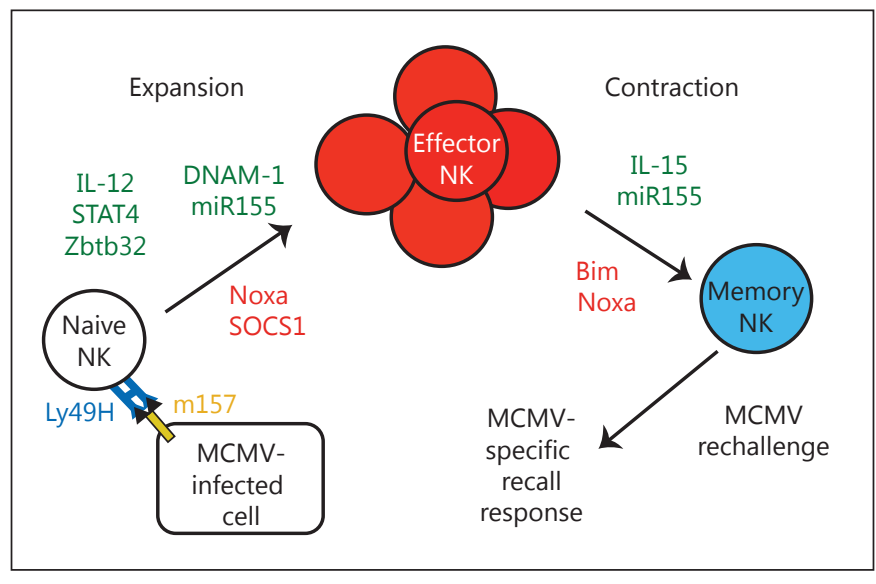

Fig. 1. Mechanisms of NK cell memory formation. During MCMV infection, naive NK cells that express the activating receptor $\mathrm{Ly} 49 \mathrm{H}$ recognize the virally encoded glycoprotein m157 on the surface of MCMV-infected host cells, resulting in the robust activation and proliferation of antigen-specific NK cells. This process is critically dependent on proinflammatory IL-12 signaling through STAT4 and Zbtb32, and costimulatory signaling through the activating receptor DNAM-1. During clonal proliferation, antigen-specific NK cells maintain viability by increasing the expression of miR155 to antagonize the prodeath factors Noxa and SOCS1; however, at the peak of virus-driven expansion, effector NK cells undergo BIMmediated cell death to form a stable pool of long-lived memory NK cells in a process that depends on endogenous IL-15. MCMV-elicited memory NK cells can respond robustly to a secondary challenge with MCMV but are less responsive to heterologous infection.

vesicular stomatitis virus, influenza $\mathrm{A}$, and human immunodeficiency virus (HIV) [28]. Furthermore, NK cells previously exposed to herpes simplex virus $2(\mathrm{HSV}-2)$ or vaccinia virus infection display enhanced IFN $-\gamma$ production and protection upon rechallenge in a process that is specific to the priming virus but independent of the adaptive immune system $[29,30]$. These studies collectively support recall responses of memory NK cells in several models but are still limited by unknown interactions between NK cell receptors and cognate pathogen-encoded antigens that may be mediating these responses. It has been reported that the activating receptor NKp46 can specifically recognize influenza hemagglutinin [31, 32], but this interaction was not reported to induce clonal expansion of NK cells in the lungs of influenza-infected mice [33]. The identification of viral antigens and their corresponding activating NK cell receptor pairs that may mediate enhanced recall responses in these models will further strengthen the concept of antigen-specific NK cell memory. 


\section{Human NK Cell Memory in Response to Viral Infections}

In humans, NK cells are essential for controlling viral infections. Patients with rare genetic deficiencies resulting in diminished NK cell numbers or function have an increased susceptibility to infection with the herpesvirus family [Epstein-Barr virus (EBV), herpes simplex virus, human cytomegalovirus (HCMV), varicella zoster virus, and human papillomavirus] [34]. Interestingly, NK cells expressing the activating CD94-NKG2C receptor are found at a higher frequency in HCMV-seropositive healthy individuals compared to HCMV-seronegative individuals $[35,36]$. Although the viral (or host) ligand induced by HCMV remains unknown, virally induced HLA-E has been shown to be critical for triggering expansion of NKG2C+ NK cells in response to HCMV [37]. Furthermore, NKG2C is likely important in the recognition of HCMV because human NKG2C+ NK cells robustly expand in allogenic transplant patients during acute HCMV infection [35, 38-40]. NKG2C and the maturation marker CD57 are also expressed at high levels in a unique subset of NK cells that remain at an increased percentage in $\mathrm{HCMV}$-seropositive individuals and further increase after HCMV reactivation [35, 38, 41]. In addition, evidence of epigenetic 'imprinting' was found at the IFN- $\gamma$ loci in NKG2C + NK cells following HCMV exposure that resembles CD8+ memory T cells and Th1 cells [42], suggesting a mechanism behind the higher IFN- $\gamma$ production by memory NK cells. In humans with a deletion in NKG2C, NK cell differentiation was compromised during HCMV infection, resulting in an altered adaptive immunity and defective control of the virus [43,44], demonstrating the importance of this receptor in defense against HCMV.

NKG2C+ NK cells have also been observed to expand in HCMV-seropositive patients with hepatitis $\mathrm{C}$ virus (HCV), hepatitis B virus (HBV), or $\operatorname{HIV}[36,45,46]$, and can rapidly proliferate following hantavirus infection to persist for over a year [47], resembling the kinetics of Ly49H+ NK cells following MCMV infection. Similar to the Ly49H+ NK cell response against MCMV infection, IL-12 (produced by inflammatory CD14+ monocytes) was implicated as a critical factor in driving the differentiation and prolific expansion of NKG2C+ NK cells through induction of CD25 in response to HCMV infection [37]. Furthermore, increased frequencies of NKG2C+ NK cells have been reported in the peripheral blood of HCMV+ children coinfected with EBV compared to HCMV+ children [48]. However, a recent longi- tudinal analysis of EBV students showed that acute EBV infection did not cause an expansion of peripheral $\mathrm{NKG} 2 \mathrm{C}+\mathrm{NK}$ cells regardless of the previous infection status with $\mathrm{HCMV}$, suggesting that the expansion of $\mathrm{NKG} 2 \mathrm{C}+\mathrm{NK}$ cells may be specific to HCMV infection rather than a generalized response to acute herpesvirus family infections [49]. Understanding the precise mechanisms underlying the expansion and persistence of these human memory NK cells could enhance the efficacy of vaccine design against HCMV, hepatitis virus, and HIV.

\section{Concluding Remarks}

We have reviewed the current evidence for virally induced memory NK cells in both mice and humans that has recently been described in the literature. These studies collectively support a model in which NK cells display virus-specific expansion to form long-lived memory cells that exhibit specific functional recall responses. Although our group and others have identified several important pathways driving the clonal proliferation of virus-specific NK cells during MCMV infection, the molecular mechanisms that govern the survival of effector NK cells during the effector-memory transition remain largely unknown. It will also be of interest to investigate whether NK cells, like CD8+ T cells, utilize self-catabolic processes such as autophagy to mediate cell survival during the contraction phase and to understand the metabolic processes utilized by NK cells during distinct phases of the response to viral infection. Future studies are needed to address other types of activating receptor-ligand driven memory NK cell formation during viral infections and whether memory NK cells can be identified by unique cell surface markers to eliminate the need for adoptive transfer model systems. Finally, both mouse and human studies are required to determine whether the NK cell compartment can be harnessed in immunization strategies against viral pathogens where no vaccine or cure currently exists.

\section{Acknowledgements}

This work was supported by the Searle Scholars Program, the Cancer Research Institute, and grants from the National Institutes of Health (AI085034 and AI100874).

\section{Disclosure Statement}

The authors declare no financial conflicts of interest. 


\section{References}

1 Williams MA, Bevan MJ: Effector and memory CTL differentiation. Annu Rev Immunol 2007;25:171-192.

2 Kondo M, Weissman IL, Akashi K: Identification of clonogenic common lymphoid progenitors in mouse bone marrow. Cell 1997;91: 661-672.

3 Di Santo JP: Natural killer cell developmental pathways: a question of balance. Annu Rev Immunol 2006;24:257-286.

4 Karo JM, Schatz DG, Sun JC: The RAG recombinase dictates functional heterogeneity and cellular fitness in natural killer cells. Cell 2014;159:94-107.

5 Sun JC, Lanier LL: NK cell development, homeostasis and function: parallels with CD8(+) T cells. Nat Rev Immunol 2011;11:645-657.

6 Orr MT, Lanier LL: Natural killer cell education and tolerance. Cell 2010;142:847-856.

7 Arase H, Mocarski ES, Campbell AE, Hill AB, Lanier LL: Direct recognition of cytomegalovirus by activating and inhibitory NK cell receptors. Science 2002;296:1323-1326.

8 Smith HR, Heusel JW, Mehta IK, Kim S, Dorner BG, Naidenko OV, Iizuka K, Furukawa H, Beckman DL, Pingel JT, Scalzo AA, Fremont DH, Yokoyama WM: Recognition of a virus-encoded ligand by a natural killer cell activation receptor. Proc Natl Acad Sci USA 2002;99:8826-8831.

9 Daniels KA, Devora G, Lai WC, O’Donnell CL, Bennett M, Welsh RM: Murine cytomegalovirus is regulated by a discrete subset of natural killer cells reactive with monoclonal antibody to Ly49H. J Exp Med 2001;194:2944.

10 Dokun AO, Kim S, Smith HR, Kang HS, Chu DT, Yokoyama WM: Specific and nonspecific NK cell activation during virus infection. Nat Immunol 2001;2:951-956.

11 Brown MG, Dokun AO, Heusel JW, Smith HR, Beckman DL, Blattenberger EA, Dubbelde CE, Stone LR, Scalzo AA, Yokoyama WM Vital involvement of a natural killer cell activation receptor in resistance to viral infection. Science 2001;292:934-937.

12 Sun JC, Beilke JN, Lanier LL: Adaptive immune features of natural killer cells. Nature 2009;457:557-561.

13 Min-Oo G, Lanier LL: Cytomegalovirus generates long-lived antigen-specific NK cells with diminished bystander activation to heterologous infection. J Exp Med 2014;211: 1289-1296.

14 O'Leary JG, Goodarzi M, Drayton DL, von Andrian UH: T cell- and B cell-independent adaptive immunity mediated by natural killer cells. Nat Immunol 2006; 7:507-516.

15 Cooper MA, Elliott JM, Keyel PA, Yang L, Carrero JA, Yokoyama WM: Cytokine-induced memory-like natural killer cells. Proc Natl Acad Sci USA 2009;106:1915-1919.
16 Sun JC, Madera S, Bezman NA, Beilke JN, Kaplan MH, Lanier LL: Proinflammatory cytokine signaling required for the generation of natural killer cell memory. J Exp Med 2012; 209:947-954.

17 Beaulieu AM, Zawislak CL, Nakayama T, Sun JC: The transcription factor Zbtb32 controls the proliferative burst of virus-specific natural killer cells responding to infection. Nat Immunol 2014;15:546-553.

18 Nabekura T, Kanaya M, Shibuya A, Fu G, Gascoigne NR, Lanier LL: Costimulatory molecule DNAM-1 is essential for optimal differentiation of memory natural killer cells during mouse cytomegalovirus infection. Immunity 2014;40:225-234.

19 Marrack P, Kappler J: Control of T cell viability. Annu Rev Immunol 2004;22:765-787.

20 Grayson JM, Zajac AJ, Altman JD, Ahmed R: Cutting edge: increased expression of Bcl-2 in antigen-specific memory CD8+ T cells. J Immunol 2000;164:3950-3954.

21 Hildeman DA, Zhu Y, Mitchell TC, Bouillet P, Strasser A, Kappler J, Marrack P: Activated $\mathrm{T}$ cell death in vivo mediated by proapoptotic bcl-2 family member bim. Immunity 2002; 16 : 759-767.

22 Prlic M, Bevan MJ: Exploring regulatory mechanisms of CD8+ T cell contraction. Proc Natl Acad Sci USA 2008;105:16689-16694.

23 Min-Oo G, Bezman NA, Madera S, Sun JC, Lanier LL: Proapoptotic Bim regulates antigen-specific NK cell contraction and the generation of the memory NK cell pool after cytomegalovirus infection. J Exp Med 2014;211: 1289-1296.

24 Firth MA, Madera S, Beaulieu AM, Gasteiger G, Castillo EF, Schluns KS, Kubo M, Rothman PB, Vivier E, Sun JC: Nfil3-independent lineage maintenance and antiviral response of natural killer cells. J Exp Med 2013;210:29812990.

25 Zawislak CL, Beaulieu AM, Loeb GB, Karo J, Canner D, Bezman NA, Lanier LL, Rudensky AY, Sun JC: Stage-specific regulation of natural killer cell homeostasis and response against viral infection by microRNA-155. Proc Natl Acad Sci USA 2013;110:6967-6972.

26 Puleston DJ, Zhang H, Powell TJ, Lipina E, Sims S, Panse I, Watson AS, Cerundolo V, Townsend AR, Klenerman P, Simon AK: Autophagy is a critical regulator of memory CD8(+) T cell formation. Elife 2014;3.

27 Sun JC, Xu T, Zuo Q, Wang RB, Qi AQ, Cao WL, Sun AJ, Sun XJ, Xu J: Hydrogen-rich saline promotes survival of retinal ganglion cells in a rat model of optic nerve crush. PLoS One 2014;9:e99299.

28 Paust S, Gill HS, Wang BZ, Flynn MP, Moseman EA, Senman B, Szczepanik M, Telenti A, Askenase PW, Compans RW, von Andrian $\mathrm{UH}$ : Critical role for the chemokine receptor CXCR6 in NK cell-mediated antigen-specific memory of haptens and viruses. Nat Immunol 2010;11:1127-1135.
29 Abdul-Careem MF, Lee AJ, Pek EA, Gill N, Gillgrass AE, Chew MV, Reid S, Ashkar AA: Genital HSV-2 infection induces short-term NK cell memory. PLoS One 2012;7:e32821.

30 Gillard GO, Bivas-Benita M, Hovav AH, Grandpre LE, Panas MW, Seaman MS, Haynes BF, Letvin NL: Thy1+ NK [corrected] cells from vaccinia virus-primed mice confer protection against vaccinia virus challenge in the absence of adaptive lymphocytes. PLoS Pathog 2011;7:e1002141.

31 Gazit R, Gruda R, Elboim M, Arnon TI, Katz G, Achdout H, Hanna J, Qimron U, Landau G, Greenbaum E, Zakay-Rones Z, Porgador A, Mandelboim O: Lethal influenza infection in the absence of the natural killer cell receptor gene Ncr1. Nat Immunol 2006;7:517-523.

32 Draghi M, Pashine A, Sanjanwala B, Gendzekhadze K, Cantoni C, Cosman D, Moretta A, Valiante NM, Parham P: NKp46 and NKG2D recognition of infected dendritic cells is necessary for NK cell activation in the human response to influenza infection. J Immunol 2007;178:2688-2698.

33 van Helden MJ, de Graaf N, Boog CJ, Topham DJ, Zaiss DM, Sijts AJ: The bone marrow functions as the central site of proliferation for long-lived NK cells. J Immunol 2012;189: 2333-2337.

34 Orange JS: Human natural killer cell deficiencies and susceptibility to infection. Microbes Infect 2002;4:1545-1558.

35 Lopez-Verges S, Milush JM, Schwartz BS, Pando MJ, Jarjoura J, York VA, Houchins JP, Miller S, Kang SM, Norris PJ, Nixon DF, Lanier LL: Expansion of a unique CD57(+) NKG2Chi natural killer cell subset during acute human cytomegalovirus infection. Proc Natl Acad Sci USA 2011;108:14725-14732.

36 Guma M, Budt M, Saez A, Brckalo T, Hengel $\mathrm{H}$, Angulo A, Lopez-Botet M: Expansion of CD94/NKG2C+ NK cells in response to human cytomegalovirus-infected fibroblasts. Blood 2006;107:3624-3631.

37 Rolle A, Pollmann J, Ewen EM, Le VT, Halenius A, Hengel $\mathrm{H}$, Cerwenka A: IL-12producing monocytes and HLA-E control HCMV-driven NKG2C+ NK cell expansion. J Clin Invest 2014;124:5305-5316.

38 Foley B, Cooley S, Verneris MR, Curtsinger J, Luo X, Waller EK, Anasetti C, Weisdorf D, Miller JS: Human cytomegalovirus (CMV)induced memory-like NKG2C(+) NK cells are transplantable and expand in vivo in response to recipient CMV antigen. J Immunol 2012;189:5082-5088.

39 Foley B, Cooley S, Verneris MR, Pitt M, Curtsinger J, Luo X, Lopez-Verges S, Lanier LL, Weisdorf D, Miller JS: Cytomegalovirus reactivation after allogeneic transplantation promotes a lasting increase in educated NKG2C+ natural killer cells with potent function. Blood 2012;119:2665-2674. 
40 Della Chiesa M, Falco M, Podesta M, Locatelli F, Moretta L, Frassoni F, Moretta A: Phenotypic and functional heterogeneity of human NK cells developing after umbilical cord blood transplantation: a role for human cytomegalovirus? Blood 2012;119:399-410.

41 Lopez-Verges S, Milush JM, Pandey S, York VA, Arakawa-Hoyt J, Pircher H, Norris PJ, Nixon DF, Lanier LL: CD57 defines a functionally distinct population of mature $\mathrm{NK}$ cells in the human CD56dimCD16+ NK-cell subset. Blood 2010;116:3865-3874.

42 Luetke-Eversloh M, Hammer Q, Durek P, Nordstrom K, Gasparoni G, Pink M, Hamann A, Walter J, Chang HD, Dong J, Romagnani C: Human cytomegalovirus drives epigenetic imprinting of the IFNG locus in NKG2Chi natural killer cells. PLoS Pathog 2014; 10:e1004441.

43 Goodier MR, White MJ, Darboe A, Nielsen CM, Goncalves A, Bottomley C, Moore SE, Riley EM: Rapid NK cell differentiation in a pop- ulation with near-universal human cytomegalovirus infection is attenuated by NKG2C deletions. Blood 2014;124:2213-2222.

44 Muntasell A, Lopez-Montanes M, Vera A, Heredia G, Romo N, Penafiel J, Moraru M, Vila J, Vilches C, Lopez-Botet M: NKG2C zygosity influences CD94/NKG2C receptor function and the NK-cell compartment redistribution in response to human cytomegalovirus. Eur J Immunol 2013;43:3268-3278.

45 Beziat V, Dalgard O, Asselah T, Halfon P, Bedossa P, Boudifa A, Hervier B, Theodorou I, Martinot M, Debre P, Bjorkstrom NK, Malmberg KJ, Marcellin P, Vieillard V: CMV drives clonal expansion of NKG2C+ NK cells expressing self-specific KIRs in chronic hepatitis patients. Eur J Immunol 2012;42:447457.

46 Brunetta E, Fogli M, Varchetta S, Bozzo L, Hudspeth KL, Marcenaro E, Moretta A, Mavilio D: Chronic HIV-1 viremia reverses NKG2A/NKG2C ratio on natural killer cells in patients with human cytomegalovirus coinfection. AIDS 2010;24:27-34.

47 Bjorkstrom NK, Lindgren T, Stoltz M, Fauriat C, Braun M, Evander M, Michaelsson J, Malmberg KJ, Klingstrom J, Ahlm C, Ljunggren HG: Rapid expansion and long-term persistence of elevated NK cell numbers in humans infected with hantavirus. J Exp Med 2011;208:13-21.

48 Saghafian-Hedengren S, Sohlberg E, Theorell J, Carvalho-Queiroz C, Nagy N, Persson JO, Nilsson C, Bryceson YT, Sverremark-Ekstrom E: Epstein-Barr virus coinfection in children boosts cytomegalovirus-induced differentiation of natural killer cells. J Virol 2013;87: 13446-13455.

49 Hendricks DW, Balfour HH Jr, Dunmire SK, Schmeling DO, Hogquist KA, Lanier LL: Cutting edge: NKG2C(hi)CD57+ NK cells respond specifically to acute infection with cytomegalovirus and not Epstein-Barr virus. Immunol 2014;192:4492-4496. 